\title{
Glass Transition in Aliphatic Ionenes
}

\author{
Tetsuo Tsursui, Toshiaki SAto, and Takehide TANAKA \\ Department of Applied Chemistry, Faculty of Engineering, \\ Kyushu University, Fukuoka, Japan.
}

(Received July 21, 1973)

\begin{abstract}
KEY WORDS. Aliphatic Ionene / Glass Transition / Mechanical Properties / Torsional Braid Analysis / Spacing of Ions / Molecular Weight /
\end{abstract}

The synthesis of aliphatic ionenes has been studied by Rembaum, et $a .^{1,2}$ Only a few investigations, however, have been reported on their physical properties, owing to their high hygroscopic property. Eisenberg, et al., ${ }^{3}$ measured the glass transition temperatures $\left(T_{\mathrm{g}}\right)$ of the aliphatic ionene-plasticizer systems by using DSC, and obtained $T_{\mathrm{g}}$ for nonplasticized polymers by extrapolation. By the use of a torsional braid analysis (TBA) instrument, we succeeded in observing directly the dynamic mechanical properties of several ionenes and the $T_{\mathrm{g}}$ values of nonplasticized polymers.

The structure of the aliphatic ionenes studied is as follows:<smiles>CC(C)(Br)CCCCCCCC[N+](C)(C)C</smiles>

A polymer with this structure is called an $m, n$ ionene. Six different ionenes were prepared by the method described by Rembaum. ${ }^{2}$ The intrinsic viscosities of these polymers were $0.04-0.10 \mathrm{~d} l / \mathrm{g}$ in $0.4-M \mathrm{KBr}$ aqueous solutions. The dynamic mechanical properties were measured by a Chemical Instrument Co. torsional braid analyser, Model 100-B1. A glass-fiber braid was immersed in a ca. 30\% aqueous solution of the polymer and dried under vacuum. Then the braid was set in an environmental chamber of the TBA instrument, and dried again under vacuum at a temperature above $T_{\mathrm{g}}$. This procedure insured that the measurements were made on perfectly dried states. After the introduction of dry $\mathrm{N}_{2}$ gas, the measurements were performed at a heating rate of $1^{\circ} \mathrm{C} / \mathrm{min}$.

Figure 1 shows the temperature dependence of the relative rigidity and the damping index of four ionenes. A dispersion was observed in the region of $90-140^{\circ} \mathrm{C}$ for each polymer, except 6, 6 ionene. Each dispersion was observed at the same temperature for both heating and cooling runs. The 6,6 ionene, which had no dispersion in its TBA measurement, showed a very distinct $\mathrm{X}$-ray diffraction pattern in com-

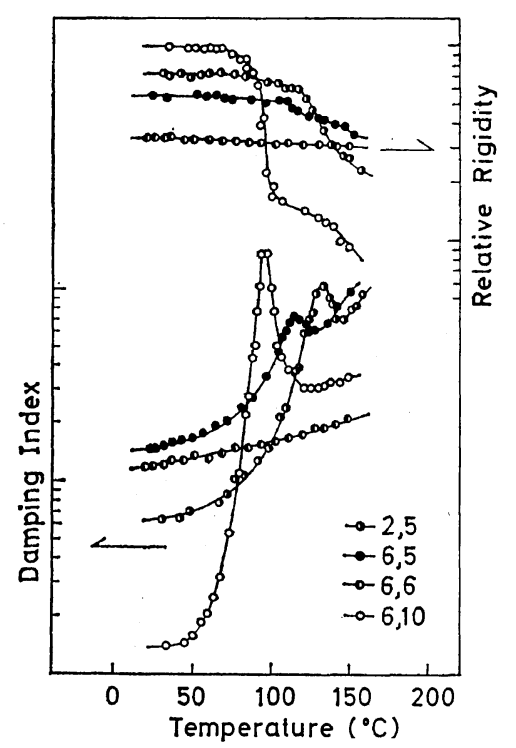

Figure 1. Temperature dependence of the relative rigidity and the damping index of aliphatic ionenes. Curves are arbitrarily vertically shifted. $(m, n)$ in the figure refers to $m, n$ ionene. 
parison with the other ionenes, which indicated high crystallinity. From these results, the dispersion can be attributed to the initiation of micro-Brownian motions of the chains in the amorphous regions. Since the measuring frequency of TBA, which varies from $0.4 \mathrm{~Hz}$ (room temperature) to $0.2 \mathrm{~Hz}$ (absorption maximum), is very low, we can regard the absorption maximum temperatures as the static $T_{\mathrm{g}}$ 's. Thus the absorption maximum temperatures are called $T_{\mathrm{g}}$ 's in this communication.

Our directly measured $T_{\mathrm{g}}$ values lie between 90 and $140^{\circ} \mathrm{C}$, whereas the values of $T_{\mathrm{g}}$ reported previously for the same ionenes, which were obtained by extrapolations from the $\mathrm{H}_{2} \mathrm{O}$ plasticized ionene systems, fell between -20 and $0^{\circ} \mathrm{C}^{3} \quad$ The effects of $\mathrm{H}_{2} \mathrm{O}$ on $T_{\mathrm{g}}$ in 6,10 ionene were examined with the TBA method in order to clarify the causes of discrepancy. Figure 2

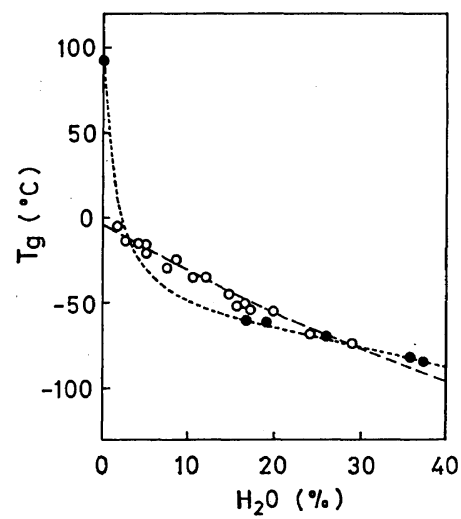

Figure 2. Variation of $T_{\mathrm{g}}$ with $\mathrm{H}_{2} \mathrm{O}$ content for 6, 10 ionene (filled circles). Data reported by Eisenberg, et al.,3 for 6,8 ionene (open circles); broken line indicates their extrapolation.

shows the variation of $T_{\mathrm{g}}$ with $\mathrm{H}_{2} \mathrm{O}$ content in 6,10 ionene. In the same figure, the values of 6, 8 ionene from the paper of Eisenberg, et al., are included. There is no significant difference between the data except in the region of extremely low $\mathrm{H}_{2} \mathrm{O}$ content. Eisenberg and his coworkers used the equation of $T_{\mathrm{g}}$ of plasticized systems for extrapolating to zero $\mathrm{H}_{2} \mathrm{O}$ content. Their extrapolation now seems rather to give estimates for the amorphous and ionized state of the ionenes. The abnormal plasticizing effects on the ionenes in the region of low plasticizer content seem to be related to the change of polymer conformations.

In Figure 3, the effects of molecular weight on $T_{\mathrm{g}}$ are shown. It is clear that the $T_{\mathrm{g}}$ values obtained in this study are not influenced by the chain ends. Following the $[\eta]-M_{w}$ relation of 6,6 ionene reported by Casson, ${ }^{4}$ the weightaverage molecular weight of 6,5 ionene with $[\eta]=0.05 \mathrm{~d} l / \mathrm{g}$ is estimated to be about 2000 . It is quite characteristic that the molecular-weight dependence on $T_{\mathrm{g}}$ is much smaller than that for nonionic organic polymers.

In Figure 4 , the $T_{\mathrm{g}}$ values determined are

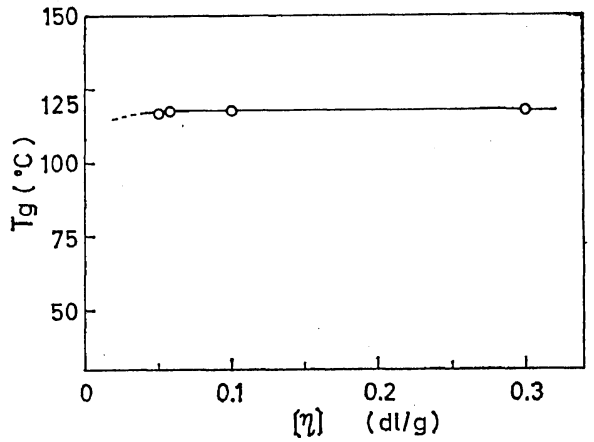

Figure 3. The effects of molecular weight on $T_{\mathrm{g}}$ $(6,5$ ionene). [ $\eta]$ was measured in $0.4-M \mathrm{KBr}$ aqueous solution.

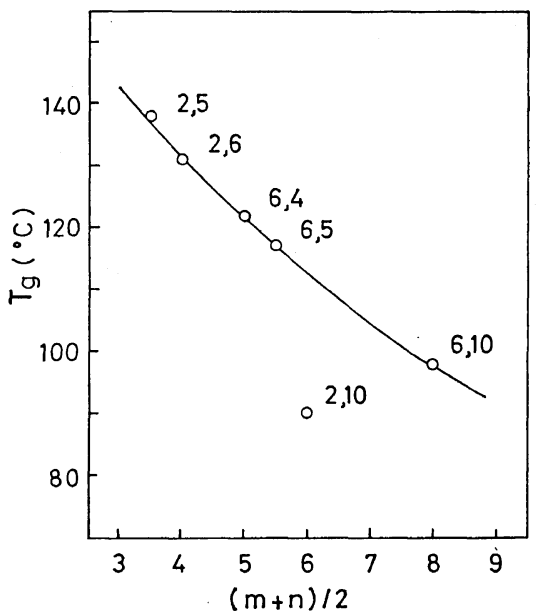

Figure 4. Variation of $T_{\mathrm{g}}$ with average spacing of the ions. $(m, n)$ in the figure indicates $m, n$ ionene. 
plotted as a function of $(m+n) / 2$, which is the average spacing of the ions. $T_{\mathrm{g}}$ increases systematically as $(m+n) / 2$ decreases, except for 2,10 ionene. Because $(m+n) / 2$ is approximately proportional to the inverse of the ionic concentration in polymers, this behavior can be understood as an effect of the strong ionic fields. The reason why the behavior of 2,10 ionene differs from the others is not very clear, but in this particular ionene the lack of uniformity of the ionic spacing may have made $(m+n) / 2$ an unsuitable measure. The work to get more extensive data and to interpret those results from the view point of molecular structures is in progress.
Acknowledgement. The authors wish to thank Prof. Tetsuo Yokoyama of the Department of Materials Science, Nagasaki University, for helpful Discussions.

\section{REFERENCES}

1. A. Rembaum, W. Baumgartner, and A. Eisenberg, J. Polym. Sci. Part B, 6, 159 (1968).

2. A. Rembaum, H. Rile, and R. Somano, ibid. Part B, 8, 457 (1970).

3. A. Eisenberg, H. Matsuura, and T. Yokoyama, Polymer J., 2, 117 (1971).

4. D. Casson and A. Rembaum, Macromolecules, 5, 75 (1972). 